\title{
Effect of ultraviolet treatment on bacterial attachment and osteogenic activity to alkali- treated titanium with nanonetwork structures
}

This article was published in the following Dove Press journal:

International Journal of Nanomedicine

28 June 2017

Number of times this article has been viewed

\section{Honghao Zhang ${ }^{1,2}$ \\ Satoshi Komasa' \\ Chiho Mashimo ${ }^{3}$ \\ Tohru Sekino ${ }^{4}$ \\ Joji Okazaki'}

'Department of Removable Prosthodontics and Occlusion, Osaka Dental University, Hirakata, Osaka, Japan; '2Department of Stomatology, Nanfang Hospital and College of Stomatology, Southern Medical University, Guangzhou, Guangdong, China; ${ }^{3}$ Department of Bacteriology, Osaka Dental University, Hirakata,

${ }^{4}$ The Institute of Scientific and Industrial Research, Osaka University, Suita, Osaka, Japan
Correspondence: Honghao Zhang

Department of Removable Prosthodontics and Occlusion, Osaka Dental University, 8-I Kuzuha-hanazonocho, Hirakata, Osaka 573-I I2I, Japan

Tel +8I 728643036

Fax +8I 69101044

Email joecheung_asuka@hotmail.com
Purpose: Alkali-treated titanium with nanonetwork structures (TNS) possesses good osteogenic activity; however, the resistance of this material to bacterial contamination remains inadequate. As such, TNS implants are prone to postoperative infection. In this work, we attempted to alter the biological properties of TNS by treatment with short-duration high-intensity ultraviolet (UV) irradiation.

Methods: TNS discs were treated with UV light (wavelength $=254 \mathrm{~nm}$, strength $=100 \mathrm{~mW} / \mathrm{cm}^{2}$ ) for 15 minutes using a UV-irradiation machine. We carried out a surface characterization and evaluated the discs for bacterial film formation, protein adsorption, and osteogenic features.

Results: The superhydrophilicity and surface hydrocarbon elimination exhibited by the treated material (UV-treated titanium with a nanonetwork structure [UV-TNS]) revealed that this treatment effectively changed the surface characteristics of TNS. Notably, UV-TNS also showed reduced colonization by Actinomyces oris during an initial attachment period and inhibition of biofilm formation for up to 6 hours. Moreover, compared to conventional TNS, UV-TNS showed superior osteogenic activity as indicated by increased levels of adhesion, proliferation, alkaline phosphatase activity, osteogenic factor production, and osteogenesis-related gene expression by rat bone marrow mesenchymal stem cells (rBMMSCs). This inverse relationship between bacterial attachment and cell adhesion could be due to the presence of electron-hole pairs induced by high-intensity UV treatment.

Conclusion: We suggest that simple UV treatment has great clinical potential for TNS implants, as it promotes the osseointegration of the TNS while reducing bacterial contamination, and can be conducted chair-side immediately prior to implantation.

Keywords: implant, nanonetwork, postoperative infection, UV treatment, superhydrophilicity, osteointegration

\section{Introduction}

Titanium is the most extensively applied biomedical implant material worldwide because of its high mechanical resistance, anticorrosive property, and biocompatibility. ${ }^{1}$ Titanium implants have an implant survival rate of $98.8 \%$ and a success rate of $97.0 \%$ over 10 years. ${ }^{2}$ However, as a short-term complication, postoperative infections adjacent to titanium implants, which typically occur within the first month after implant insertion, remain a significant concern, as such infections can eventually lead to early implant failure. Indeed, the incidence of infection for titanium implants is $\sim 10 \%$, and nearly two-thirds of infected implants fail before functional loading. ${ }^{3}$ Importantly, dental implant surgery cannot be performed under thoroughly sterile conditions as the oral cavity is inhabited by $>600$ bacterial species. ${ }^{4}$ Oral bacteria can adhere to the implant surface during the insertion 
process or enter the oral mucosa wound after operation. Although antibiotics are generally applied to decrease the risk of postoperative infections, their effectiveness in this context remains controversial. ${ }^{5}$ Hence, avoiding bacterial contamination during and after implant surgical operations is paramount for successful osseointegration.

As a novel type of biomaterial that can potentially be used in dental and orthodontic implants, alkali-treated titanium surfaces with nanostructures have recently received a great deal of attention. In our previous study, we demonstrated that high concentrations of alkali-treated titanium can produce a basic, hydrophilic sodium titanate layer with nanonetwork structures, termed titanium with nanonetwork structures (TNS). In addition to its enhanced osteogenic activity, advantages of TNS include the room temperature synthesis, environmental friendliness, controllability of reaction conditions, low energy consumption (no heat treatment needed), and low cost. Thus, high-concentration alkali treatment is considered a suitable synthetic route for producing TNS. ${ }^{6,7}$ However, several challenges remain to be addressed prior to the clinical application of this material. In particular, alkalitreated titanium with nanostructures exhibits insufficient resistance to bacterial attachment, ${ }^{8}$ which could engender postoperative infection after implant insertion.

A variety of surface modification methods have been evaluated in attempts to produce an implant surface that exhibits good biological compatibility and antimicrobial activity. To date, however, only a few simple and effective methods have been developed. ${ }^{9}$ In recent years, ultraviolet (UV) treatment of dental implant materials has received increasing attention because of its extreme simplicity and effectiveness. UV treatment enables more rapid bone cell adhesion, proliferation, and differentiation, as well as more complete osseointegration between titanium and bone in vivo. ${ }^{10-14}$ UV-treated titanium also attains superhydrophilicity and reduced hydrocarbon contamination, which might explain its excellent biological compatibility. Surprisingly, UV treatment has also been shown to reduce bacterial attachment and biofilm formation on titanium and titanium alloy surfaces. ${ }^{15,16}$ Nevertheless, while the effects of UV treatment can last for 16-48 hours, its inhibitory effect will slowly disappear when exposed to air owing to the loss of superhydrophilicity and the increase in carbon components, which restricts its clinical application. Currently, superhydrophilicity is rendered to titanium surfaces via a 12-minute UV treatment, preventing biofilm formation for up to 16 hours. ${ }^{17}$ This short treatment time allows for the treatment of implants chair-side as well as for immediate insertion of treated implants onto the bone. Therefore, we hypothesized that UV treatment would yield reduced rates of postoperative infection and superior osteogenic activity for TNS.

In the present study, we employed a novel high-intensity UV irradiation technique to provide a rapid method for changing the biological properties of TNS (UV-treated titanium with nanonetwork structures [UV-TNS]). Actinomyces oris, a known initial colonizer in the oral ecosystem ${ }^{18}$ and one of the most prevalent species in shallow, deep, and very deep pockets of patients ${ }^{19}$ with periodontitis, was utilized as a model organism to evaluate the levels of initial attachment and biofilm formation on UV-TNS. Meanwhile, rat bone marrow mesenchymal stem cells (rBMMSCs) were utilized for analyses of osteogenic activity, as these cells are at the forefront of the osseointegration process. ${ }^{20}$ To the best of our knowledge, the effects of UV irradiation on bacterial attachment to, and osteogenic activity of, TNS have not been widely studied. We anticipate that our results will provide a useful and significant reference for the clinical application of UV-TNS.

\section{Materials and methods}

\section{Sample preparation}

Titanium discs (15 $\mathrm{mm}$ in diameter and $1 \mathrm{~mm}$ in thickness) of grade 2 commercially pure titanium were successively polished using several grades of $\mathrm{SiC}$ abrasive papers (600\#, $800 \#, 1,000 \#$, and 1,500\#). The discs were then ultrasonically cleaned in acetone, ethanol, and deionized water (each for 10 minutes) and dried at room temperature overnight. For the production of TNS, polished and cleaned discs were immersed in $10 \mathrm{M} \mathrm{NaOH}$ at $30^{\circ} \mathrm{C}$ for 24 hours and rinsed several times with ion-exchanged water until the solution reached a conductivity of $<5 \mu \mathrm{S} / \mathrm{cm}^{3}$. All discs were subjected to dry heat sterilization.

\section{UV treatment of TNS}

Half of the TNS discs were treated with UV light (wavelength $=254 \mathrm{~nm}$, strength $=100 \mathrm{~mW} / \mathrm{cm}^{2}$ ) for 15 minutes using a UV irradiation machine (HL-2000 HybriLinker; Funakoshi, Tokyo, Japan). Irradiated discs were divided into the following three treatment groups: Ti (pure titanium), TNS, and UV-TNS. The irradiated discs were used in experiments within 30 minutes after UV treatment. For all biological experiments, Ti was used as a positive control.

\section{Surface characterization}

For surface topography analysis, TNS and UV-TNS were examined by scanning electron microscopy (SEM) (S-4800; Hitachi, Tokyo, Japan). Contact angles were measured using 
a contact angle measurement system (VSA 2500 XE; AST Products, Billerica, MA, USA) after application of $2 \mu \mathrm{L}$ of $\mathrm{ddH}_{2} \mathrm{O}$ to the sample surface at room temperature. To determine the elemental composition of the TNS surface and to evaluate changes in this composition after UV treatment, samples were subjected to X-ray photoelectron spectroscopy (XPS; Kratos Axis Ultra, Shimadzu, Japan).

\section{Bacterial cultivation}

A. oris strain MG-1 was used for bacterial attachment experiments. Briefly, the organism was streaked onto Brucella agar and incubated at $37^{\circ} \mathrm{C}$ for 48 hours under aerobic conditions. A single colony was subsequently picked and cultivated in $2 \mathrm{~mL}$ of liquid Brucella broth overnight with shaking. This seed culture was then diluted in fresh Brucella broth to an optical density at $600 \mathrm{~nm}$ of 0.6 (equal to $2 \times 10^{8} \mathrm{cfu} / \mathrm{mL}$ ) and utilized in initial attachment and biofilm formation assays.

\section{Analysis of initial bacterial attachment by confocal laser-scanning microscopy and SEM}

Prior to bacterial attachment assays, sample discs were placed in standard 24-well polystyrene culture plates. One milliliter of bacterial suspension was added to each disc, and the plates were incubated aerobically at $37^{\circ} \mathrm{C}$ for 1 or 6 hours to allow initial attachment and biofilm formation, respectively. After the 1-hour incubation, the bacterial suspension was removed and sample discs were gently transferred into a new 12-well polystyrene culture plate and rinsed with $2 \mathrm{~mL}$ of sterile phosphate-buffered saline (PBS) to dislodge and remove unattached bacteria. Then, the discs were transferred to a new 12-well polystyrene culture plate and stained using a Live/Dead ${ }^{\circledR}$ BacLight $^{\mathrm{TM}}$ Bacterial Viability Kit (L7012; Thermo Fisher Scientific, Waltham, MA, USA), according to the manufacturer's instructions. In brief, $3.0 \mu \mathrm{L}$ of the SYTO 9/propidium iodide (PI) stain solution was mixed thoroughly in a $1.5 \mathrm{~mL}$ microfuge tube and diluted in $1 \mathrm{~mL}$ of PBS. One milliliter of the dye solution was added onto each sample disc after which the discs were incubated at room temperature for at least 15 minutes in the dark. Then, the dye solution was removed, and the samples were placed on a cover glass $(18 \times 18 \mathrm{~mm}, 0.1 \mathrm{~mm}$ thick; Matsunami Glass Ind., Osaka, Japan). Bacteria were visualized and photographed using a confocal laser-scanning microscope (LSM700; Carl Zeiss, Oberkochen, Germany) immediately after staining, and images were analyzed using ImageJ software (National Institutes of Health, Bethesda, MD, USA). In this assay, SYTO 9 is capable of penetrating the cell membranes of all bacteria to stain nucleic acid, while PI is only able to penetrate and label dead bacteria. ${ }^{9}$

For SEM analyses, bacteria were cultivated on discs as described above, rinsed with PBS to remove unattached bacteria, and fixed with $2 \%$ glutaraldehyde for 2 hours, followed by $1 \%$ osmium tetroxide for 15 minutes. Then, the samples were subjected to sequential dehydration with a graded series of ethanol solutions $(50 \%, 60 \%, 70 \%, 80 \%$, $90 \%, 99 \%$, and anhydrous ethanol) for 10 minutes each. Prior to observation, the discs were dried in a critical point dryer (HCP-1; Hitachi) and coated with platinum-palladium using an ion sputter machine (Ion sputter E-1030; Hitachi).

\section{Analysis of bacterial biofilm formation by crystal violet staining}

After the 6-hour incubation described in the "Analysis of initial bacterial attachment by confocal laser-scanning microscopy and SEM" section, bacterial suspensions were removed, and sample discs were gently transferred into a new 12-well polystyrene culture plate and rinsed with $2 \mathrm{~mL}$ of sterile PBS. The samples were incubated with $2 \mathrm{~mL}$ of $0.05 \%(\mathrm{w} / \mathrm{v})$ crystal violet dye solution for 20 minutes at room temperature. After staining, discs were rinsed three times with $2 \mathrm{~mL}$ of PBS to remove residual dye, transferred to a new 12-well plate, and destained by incubation in $1 \mathrm{~mL}$ $95 \%$ ethanol for 20 minutes at room temperature with rotatory shaking at $40 \mathrm{rpm}$. After destaining, $100 \mu \mathrm{L}$ of ethanol was transferred to each well and the absorbance at $595 \mathrm{~nm}$ was determined using a SpectraMax M5 96-well microplate reader (Molecular Devices LLC, Sunnyvale, CA, USA).

\section{Protein adsorption assay}

Human fibronectin (Nacalai Tesque Inc., Tokyo, Japan) was used as a model protein; $200 \mu \mathrm{L}$ of human fibronectin solution $(500 \mu \mathrm{g} / \mathrm{mL})$ was pipetted onto each sample disc. After incubation at $37^{\circ} \mathrm{C}$ for 3,6 , or 24 hours, nonadherent proteins were removed, mixed with bicinchoninic acid (Pierce Biotechnology, Waltham, MA, USA) according to the manufacturer's protocol, and incubated at $37^{\circ} \mathrm{C}$ for 30 minutes. The amount of the removed human fibronectin and the total amount of inoculated human fibronectin were quantified at $562 \mathrm{~nm}$ using a microplate reader (SpectraMax M5; Molecular Devices).

\section{Cell culture}

rBMMSCs were obtained from the femurs of 8-week-old Sprague-Dawley rats (SHIMIZU Laboratory Supplies Co., Kyoto, Japan), maintained in Eagle's minimum essential 
medium (E-MEM) containing 10\% fetal bovine serum (FBS) and an antibiotic-antimycotic solution (all from Nacalai Tesque), and cultured in a humidified atmosphere with $5 \% \mathrm{CO}_{2}$ at $37^{\circ} \mathrm{C}$. The medium was replaced every 3 days. When cultures reached a confluency of $\sim 80 \%$, rBMMSCs were treated with a solution containing $0.5 \mathrm{~g} / \mathrm{L}$ trypsin and $0.53 \mathrm{mmol} / \mathrm{L}$ EDTA (Nacalai Tesque) and added to 12-well plates containing Ti, TNS, and UV-TNS discs at a density of $4 \times 10^{4}$ cells/well. The culture medium was subsequently renewed every 3 days.

\section{Cell adhesion and proliferation}

Cell adhesion was analyzed at 3 and 24 hours, while cell proliferation was analyzed at 3 and 7 days using a CellTiterBlue ${ }^{\circledR}$ Cell Viability Assay (Promega Corporation, Madison, WI, USA), according to the manufacturer's protocol. After culturing, the samples were washed with PBS and treated with $300 \mu \mathrm{L}$ of diluted CellTiter-Blue ${ }^{\circledR}$ Reagent $(50 \mu \mathrm{L}$ CellTiter-Blue ${ }^{\circledR}$ Reagent diluted in $250 \mu \mathrm{L}$ PBS). After a 1 -hour incubation at $37^{\circ} \mathrm{C}, 100 \mu \mathrm{L}$ of the reagent from each well was added to a new 96-well tissue culture plate and fluorescence was recorded at 560/590 nm using a microplate reader (SpectraMax M5; Molecular Devices).

\section{Cell morphology}

After culturing for 24 hours, samples were washed with PBS, fixed by incubation in $4 \%$ paraformaldehyde solution for 20 minutes at room temperature, and permeabilized with $0.2 \%(\mathrm{v} / \mathrm{v})$ Triton $\mathrm{X}-100$ for 30 minutes at room temperature. Then, the cells were incubated with Blocking One reagent (Nacalai Tesque) for 30 minutes at room temperature and stained with phalloidin and 4',6-diamidino-2-phenylindole (DAPI) at $37^{\circ} \mathrm{C}$ in darkness for 1 hour. F-actin and cell nuclei were examined using a confocal laser-scanning microscope (LSM700; Carl Zeiss).

\section{Alkaline phosphatase (ALP) activity}

To evaluate the ALP activity, $4 \times 10^{4}$ cells were seeded on discs in $\alpha$-MEM (Nacalai Tesque) containing 10\% FBS, antibiotic-antimycotic mix, and the following osteogenic supplements: $10 \mathrm{mM} \beta$-glycerophosphate (Wako Pure Chemical Industries, Osaka, Japan), ascorbic acid (Nacalai Tesque), and $10 \mathrm{nM}$ dexamethasone (Nacalai Tesque). The differentiation medium was changed every 3 days. After incubation for 7 or 14 days, the samples were washed with PBS and lyzed with $300 \mu \mathrm{L}$ of $0.2 \%$ Triton X-100, and the lysates were transferred to microcentrifuge tubes. ALP activity was measured using the ALP pNPP Liquid Substrate for enzyme-linked immunosorbent assay (ELISA) Kit
(Sigma-Aldrich, St Louis, MO, USA), according to the manufacturer's protocol. The reaction was terminated by adding $50 \mu \mathrm{L}$ of $3 \mathrm{~N} \mathrm{NaOH}$ to the $200 \mu \mathrm{L}$ reaction substrate, and $p$-nitrophenol production was determined at an optical density of $405 \mathrm{~nm}$ using a 96-well microplate reader (Spec$\operatorname{traMax}^{\circledR}$ M5; Molecular Devices). The DNA content was determined using the PicoGreen dsDNA Assay Kit (Thermo Fisher Scientific), according to the manufacturer's protocol. The amount of ALP was normalized to that of DNA within the respective cell lysates.

\section{Osteocalcin production}

After differentiation for 21 or 28 days as described in the "Alkaline phosphatase (ALP) activity" section, samples were washed with PBS. Osteocalcin production was determined using a commercial ELISA kit (Rat Osteocalcin ELISA Kit DS; DS Pharma Biomedical Co, Ltd, Osaka, Japan), according to the manufacturer's instructions.

\section{Quantification of calcium deposition in the extracellular matrix}

After differentiation for 21 or 28 days as described in the "Alkaline phosphatase (ALP) activity" section, calcium deposited in the extracellular matrix was dissolved with $10 \%$ formic acid and collected. The amount of calcium was quantified using a Calcium E-Test Kit (Wako Pure Chemical Industrials). Briefly, $1 \mathrm{~mL}$ of Calcium E-Test reagent and $2 \mathrm{~mL}$ of kit buffer were added to $0.5 \mathrm{~mL}$ of sample, and the absorbance of the reaction products was measured using a 96-well microplate reader (SpectraMax ${ }^{\circledR}$ M5; Molecular Devices). The concentration of calcium ions was calculated from the absorbance value relative to a standard curve.

\section{Analysis of the expression levels of osteogenesis-related genes}

The expression levels of osteogenesis-related genes were evaluated using a real-time TaqMan reverse transcriptase polymerase chain reaction (RT-PCR) assay (Life Technologies, Carlsbad, CA, USA), as previously described. ${ }^{7}$ rBMMSCs were cultured on sample discs for 3, 7, 14, or 21 days. Total RNA was isolated using an RNeasy Mini Kit (Qiagen, Venlo, the Netherlands) and aliquots $(10 \mu \mathrm{L})$ of each RNA sample were reverse-transcribed into cDNA using a PrimeScript RT Reagent Kit (TaKaRa Bio, Shiga, Japan). The mRNA levels of the osteogenesis-related genes encoding ALP, runt-related transcription factor 2 (Runx2), bone morphogenetic protein (BMP), and osteopontin (OPN) were quantified using the StepOne ${ }^{\text {TM }}$ Plus RT-PCR System (Life Technologies). ALP and Runx2 expressions were 
measured at 3 and 7 days, while BMP and OPN expressions were measured at 14 and 21 days. Relative gene expression levels in each group were calculated using the $\Delta \Delta \mathrm{Ct}$ method and were normalized to that of the housekeeping gene glyceraldehyde 3-phosphate dehydrogenase (GAPDH).

\section{Statistical analysis}

Surface characterizations, bacterial experiments, and cell experiments were each conducted in triplicate. All quantitative results were expressed as means \pm standard deviations. Results were evaluated by one-way analysis of variance (ANOVA) and Bonferroni's post hoc test using SPSS 20.0 software (IBM Corporation, Armonk, NY, USA); $P<0.05$ was considered statistically significant.

\section{Results}

\section{Surface characterization}

SEM analysis detected a nanoporous network structure on the surface of the TNS discs (Figure 1A). The reticular porous network structures with an average diameter of 50-100 nm were well interconnected and uniformly distributed. UV-TNS maintained the nanoporous structure, with no significant changes.

The results of the surface hydrophilicity analysis of TNS and UV-TNS are depicted in Figure 1B. TNS exhibited a hydrophilic surface with a contact angle of $\sim 7^{\circ}$. Notably, the contact angle significantly decreased to $0^{\circ}(* * * P<0.001)$ after UV treatment, as evidenced by the immediate spreading of $\mathrm{ddH}_{2} \mathrm{O}$ across the surface of UV-TNS.

Next, TNS and UV-TNS discs were subjected to XPS analysis (Figure 2). The XPS spectrum for titanium showed a $2 \mathrm{p}_{3 / 2}$ peak at $458.8 \mathrm{eV}$ for TNS and UV-TNS, indicating that both were covered by titanate. Meanwhile, the appearance of an Na1s peak demonstrated that sodium was present on the titanium surface, likely because of the high-concentration alkali treatment. Both the Ti2p and O1s peaks were shifted on the UV-TNS spectrum as compared to the TNS spectrum. Lastly, the $\mathrm{C} 1 \mathrm{~s}$ peak and its shoulder peak (ascribed to hydrocarbon contamination) were significantly lower for UV-TNS, and the atomic percentage of carbon was decreased by $>50 \%$ on this material (Table 1), indicating that short-duration highintensity UV irradiation can effectively reduce the surface carbon composition of TNS.

\section{Bacterial attachment and biofilm formation}

To evaluate the effect of UV treatment on initial bacterial attachment, sample discs were incubated with $A$. oris strain MG-1 for 1 hour, subjected to live/dead staining, and visualized by confocal laser-scanning microscopy. Qualitative
A

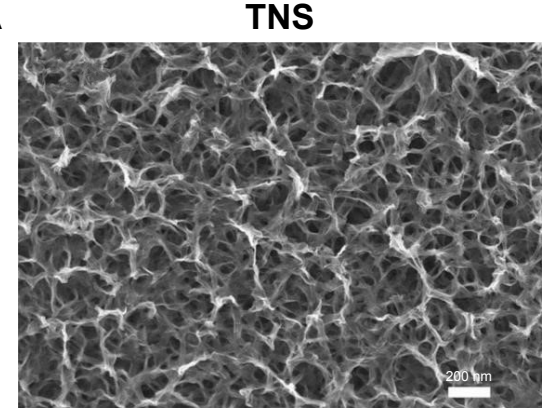

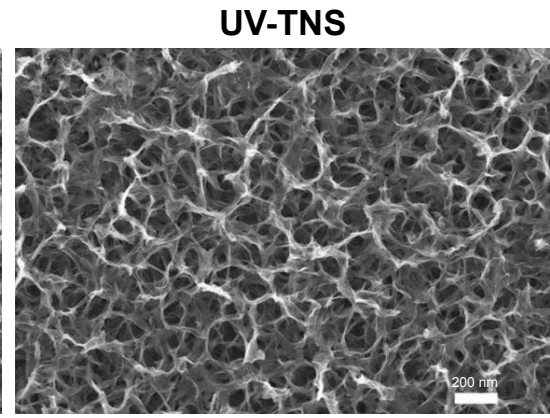

B
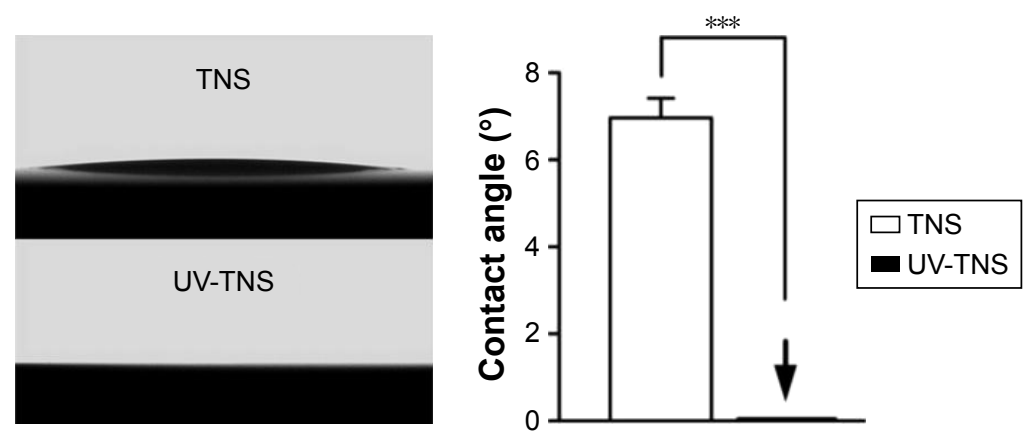

Figure I Surface characteristics of TNS and UV-TNS

Notes: (A) Surface morphology of TNS and UV-TNS by SEM (magnification $=50,000 \times$ ), scale bar $=200 \mathrm{~nm}$. (B) Comparison of contact angle measurements for TNS and UV-TNS. The contact angle of TNS and UV-TNS discs was evaluated using a VSA 2500 XE contact angle measurement system after application of $2 \mu \mathrm{LddH}{ }_{2} \mathrm{O}$ to the sample surface at room temperature $(* * * P<0.001)$.

Abbreviations: TNS, titanium with nanonetwork structures; UV-TNS, ultraviolet-treated titanium with nanonetwork structures; SEM, scanning electron microscopy. 

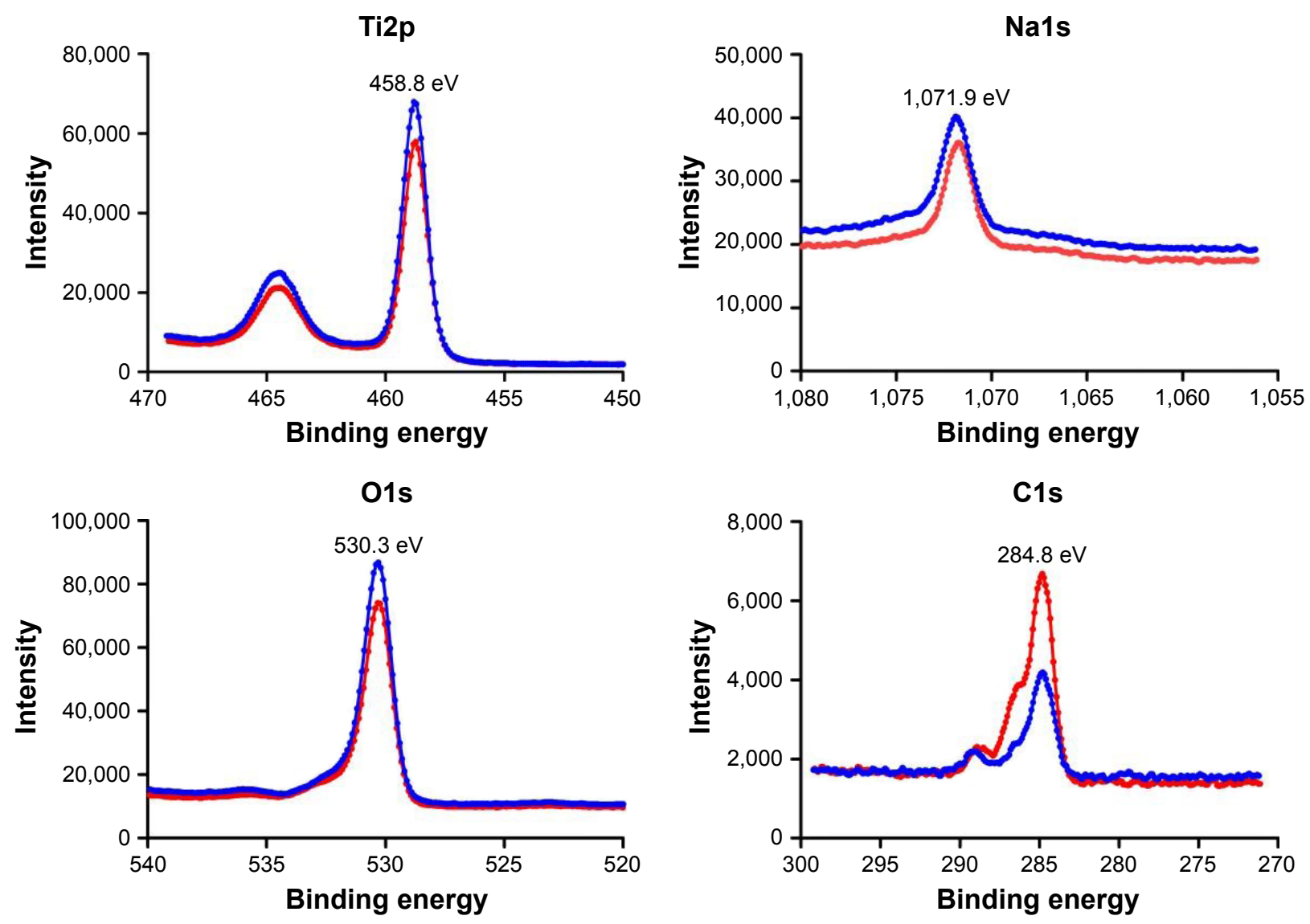

Figure 2 High-resolution chemical analysis of sample surfaces by XPS.

Note: Panels show the XPS spectra for Ti2p, NaIs, OIs, and Cls.

Abbreviations: TNS, titanium with nanonetwork structures; UV-TNS, ultraviolet-treated titanium with nanonetwork structures; XPS, X-ray photoelectron spectroscopy.

evaluation of the treated discs revealed greater numbers of attached bacteria on TNS than on Ti, while UV-TNS showed considerably lower bacterial attachment than either TNS or Ti. In addition, on each of the three types of discs, the majority of the observed bacteria stained green (live), while only a few showed red staining (dead) (Figure 3A-D).

SEM was used to further assess the morphology of bacteria attached to the sample discs. As shown in Figure 4A-C, $A$. oris MG-1 displayed a rod-like shape with a complete cell wall on both Ti and TNS; however, there were greater numbers of bacteria attached to TNS than to Ti, and these cells exhibited a clumping phenotype distinct from the single cells observed

Table I Atomic percentages of titanium, oxygen, and carbon on TNS and UV-TNS

\begin{tabular}{llll}
\hline & \multicolumn{4}{l}{ Atomic percentage } \\
\cline { 2 - 4 } & $\mathbf{T i}$ & $\mathbf{O}$ & $\mathbf{C}$ \\
\hline TNS & 22.27 & 56.22 & 19.48 \\
UV-TNS & 25.10 & 63.31 & 9.04 \\
\hline
\end{tabular}

Abbreviations: TNS, titanium with nanonetwork structures; UV-TNS, ultraviolettreated titanium with nanonetwork structures. on the Ti discs. This finding indicates that the bacteria present on TNS discs had begun to proliferate, while those on the $\mathrm{Ti}$ discs remained in the initial attachment phase. Meanwhile, no significant morphological changes were observed in the cells attached to UV-TNS, and cell clumping was not observed (Figure 4D and E). In addition, lyzed or irregular shaped bacteria were not observed on TNS or UV-TNS.

Because the first 6 hours after implantation is believed to be associated with the greatest risk of bacterial contamination and biofilm formation, an ideal treatment would be effective for at least 6 hours. Crystal violet staining was applied to evaluate biofilm formation on discs incubated with $A$. oris MG-1 for 6 hours. As shown in Figure 5, while strain MG-1 exhibited a greater level of biofilm formation on TNS than on Ti, the level of biofilm formation detected on UV-TNS was significantly lower than that on either TNS or Ti.

\section{Protein adsorption}

Both TNS and UV-TNS showed greater adsorption of human fibronectin than Ti at 3, 6, and 24 hours (Figure 6A). Notably, 

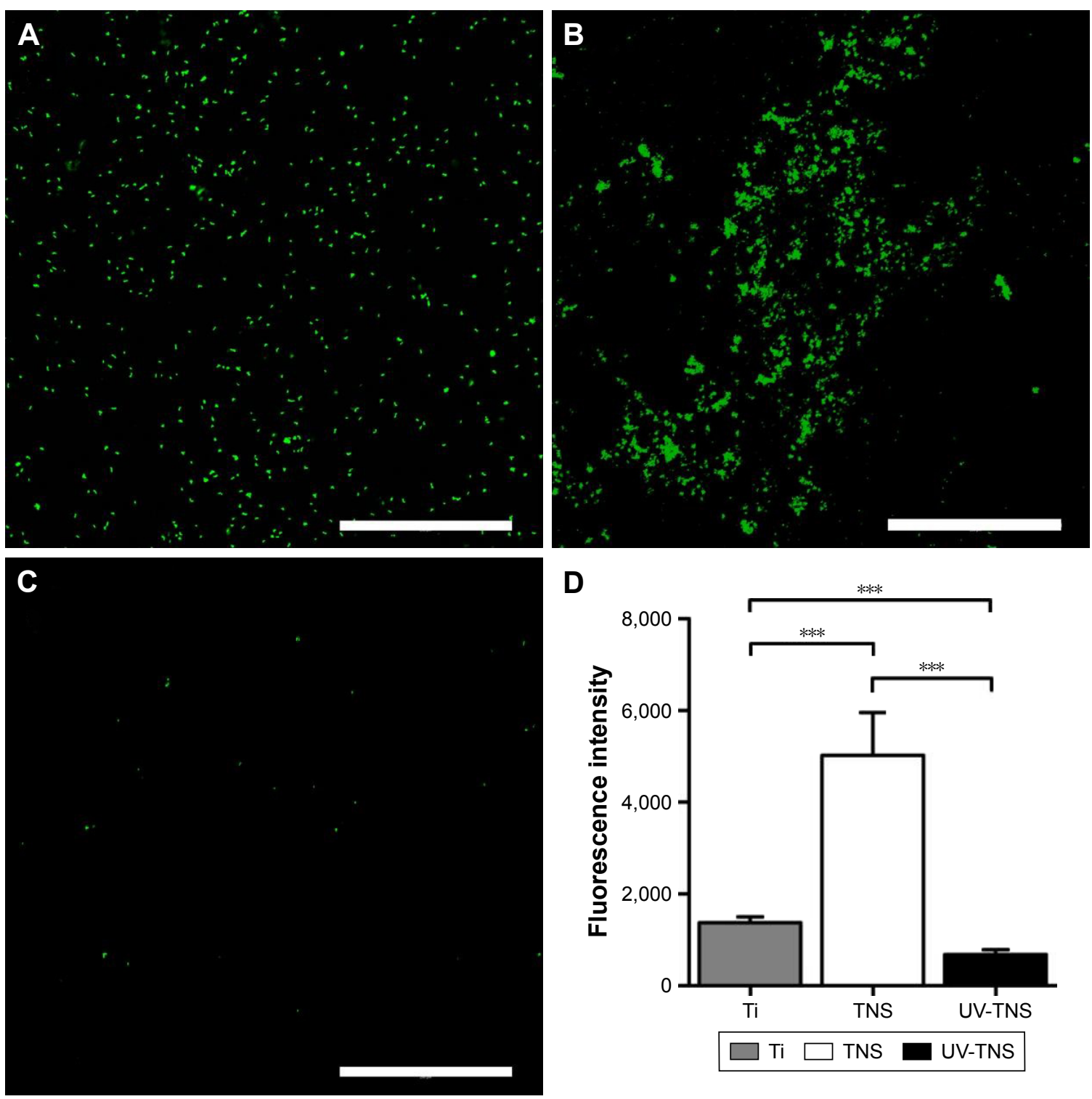

Figure 3 Live/dead staining of the bacteria attached to sample discs.

Notes: (A) Ti, (B) TNS, and (C) UV-TNS discs were incubated with A. oris strain MG-I for I hour and subjected to live/dead staining with a SYTO 9/propidium iodide solution; scale bar $=200 \mu \mathrm{m}$. (D) Comparison of the fluorescence intensity of each sample covered by fluorescent staining bacteria (***P $<0.00 \mathrm{I}$ ).

Abbreviations: A. oris, Actinomyces oris; TNS, titanium with nanonetwork structures; UV-TNS, ultraviolet-treated titanium with nanonetwork structures.

however, UV-TNS adsorbed more fibronectin than TNS during the initial adsorption phase $(* * * P<0.001)$. Although this fibronectin adsorption advantage narrowed at later stages (eg, 24 hours), UV-TNS still showed a significantly stronger adsorption than TNS $(* * P<0.01)$. This finding indicates that the rate of adsorption of fibronectin to UV-TNS slowed after 6 hours and remained similar to that of TNS thereafter.

\section{Osteogenic activity of rBMMSCs}

Cell adhesion and proliferation of rBMMSCs on sample discs were evaluated via the CellTiter-Blue ${ }^{\circledR}$ Cell Viability Assay (Figure 6B and C). Notably, UV-TNS showed higher levels of cell adhesion than TNS at 3 hours, and this trend was maintained for 24 hours. Moreover, the UV-TNS discs retained higher numbers of rBMMSCs than the TNS samples after 3 and 7 days of incubation.

Cell morphology was determined by phalloidin and DAPI staining after a 24-hour incubation (Figure 7). Compared with Ti, the rBMMSCs on both TNS and UV-TNS exhibited greater F-actin expression and more filopodial and lamelipodial extensions. Meanwhile, the rBMMSCs on UV-TNS displayed a polygonal shape and greater spreading than those on TNS, indicating that UV treatment enhances rBMMSC spreading on TNS.

After allowing cells to differentiate on sample discs for 7 or 14 days, cells grown on UV-TNS discs exhibited higher 

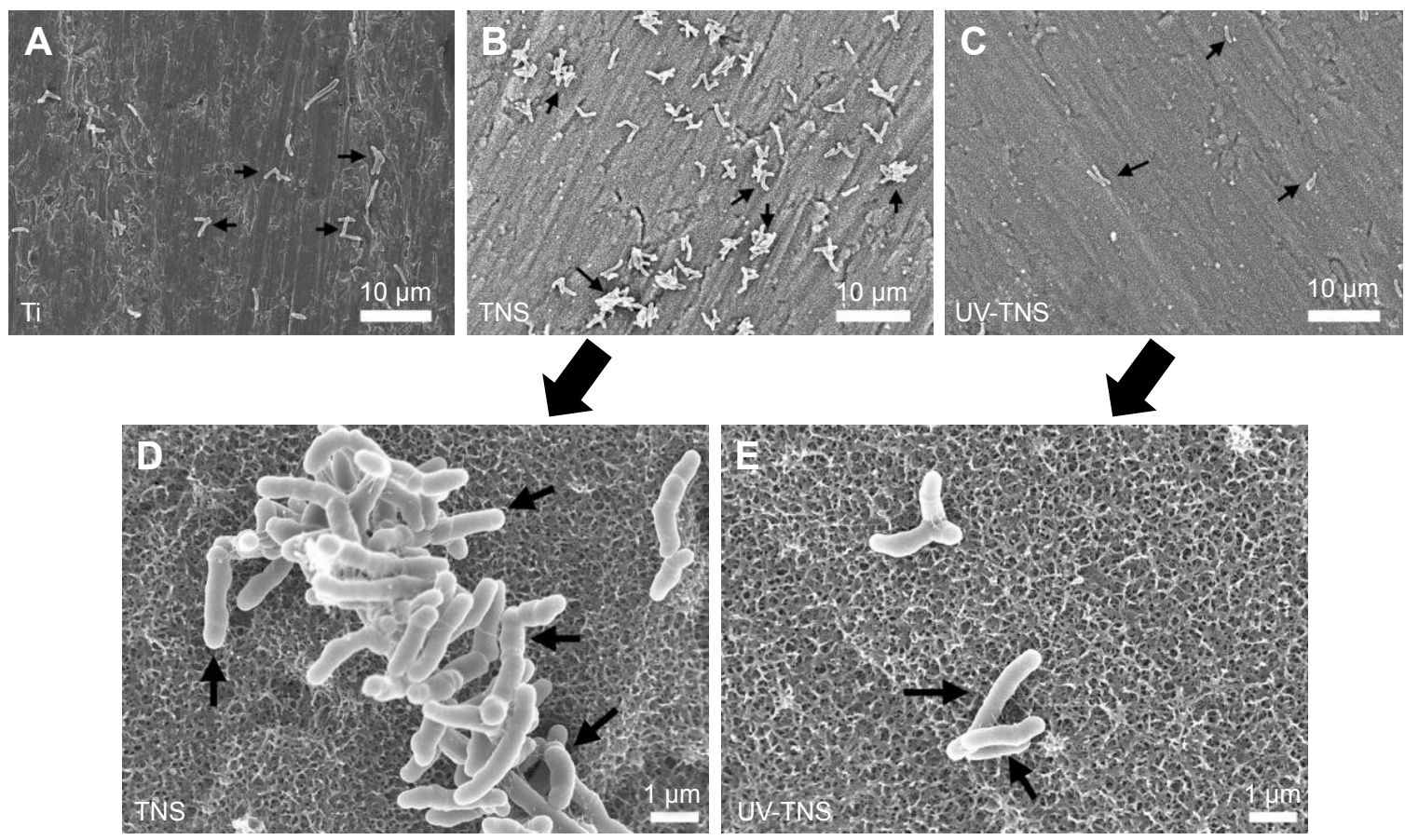

Figure 4 SEM analysis of the morphology of bacteria attached to sample discs.

Notes: (A) Ti, (B and D) TNS, and (C and E) UV-TNS discs were incubated with A. oris strain MG-I for I hour and then evaluated by SEM. Magnification: 2,000x for (A-C) $($ scale bar $=10 \mu \mathrm{m})$ and I0,000 $\times$ for $(\mathbf{D}$ and $\mathbf{E})($ scale bar $=I \mu \mathrm{m})$. A. oris MG-I displayed a rod-like shape with a complete cell wall on both TNS and UV-TNS; lyzed or irregularly shaped bacteria were not observed.

Abbreviations: A. oris, Actinomyces oris; TNS, titanium with nanonetwork structures; UV-TNS, ultraviolet-treated titanium with nanonetwork structures; SEM, scanning electron microscopy.

ALP activity per cell unit than those grown on TNS (Figure 8A). Likewise, cells cultivated on UV-TNS exhibited higher production of osteocalcin, a marker of late-stage osteogenic differentiation, and higher calcium deposition, a marker for extracellular matrix mineralization, than those grown

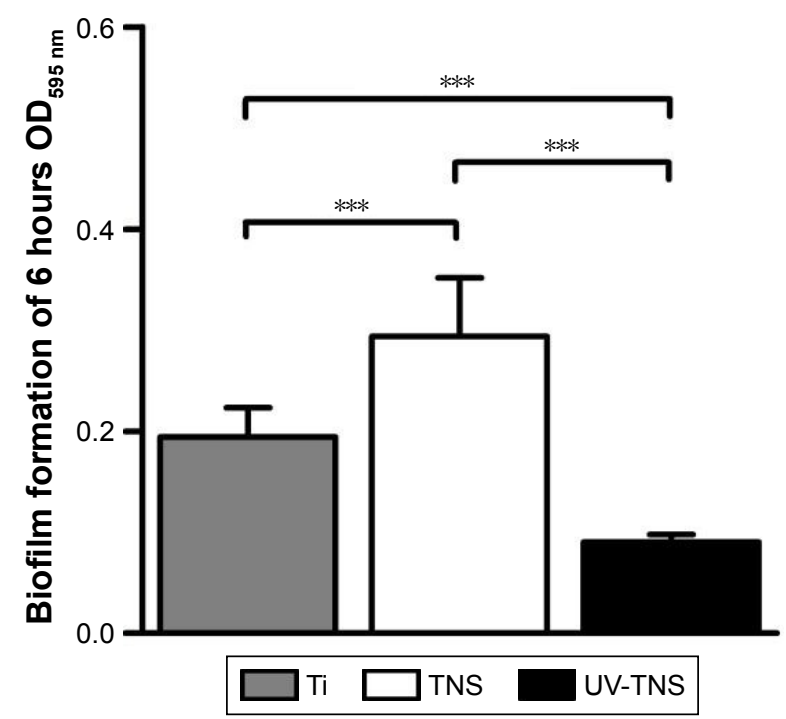

Figure 5 Bacterial biofilm formation on sample discs.

Notes: Ti, TNS, and UV-TNS discs were incubated with A. oris strain MG-I for 6 hours, and biofilm formation was evaluated by crystal violet staining (***P<0.00I).

Abbreviations: A. oris, Actinomyces oris; TNS, titanium with nanonetwork structures; UV-TNS, ultraviolet-treated titanium with nanonetwork structures; OD, optical density. on TNS discs after 21 and 28 days of differentiation (Figure 8B and C).

Lastly, the expression levels of osteogenesis-related genes on each sample disc were investigated by RT-PCR on days 3 , 7, 14, and 21 of cell incubation (Figure 9A-D). In general, cells cultivated on UV-TNS showed higher levels of gene expression than those attached to the other two samples. Specifically, the cells grown on UV-TNS exhibited considerably higher mRNA levels of $A L P$ and Runx 2 on days 3 and 7 and of $B M P$ and $O P N$ on days 14 and 21 than the cells cultivated on TNS. ALP and Runx 2 are transcription factors that are crucial for osteogenic differentiation and are expressed during the early stages of osteogenic differentiation. ${ }^{7}$ BMP and OPN are representative osteogenic products of late-stage osteogenic differentiation. Thus, these results indicate that UV treatment significantly promotes the differentiation of rBMMSCs on TNS from early to late stage.

\section{Discussion}

In this study, we demonstrated that the surface characteristics and biological properties of TNS could be modulated via short-duration high-intensity UV treatment. Specifically, this treatment endowed TNS with a superhydrophilic surface and eliminated surface hydrocarbon contamination. Although a significant increase in initial bacterial attachment was 

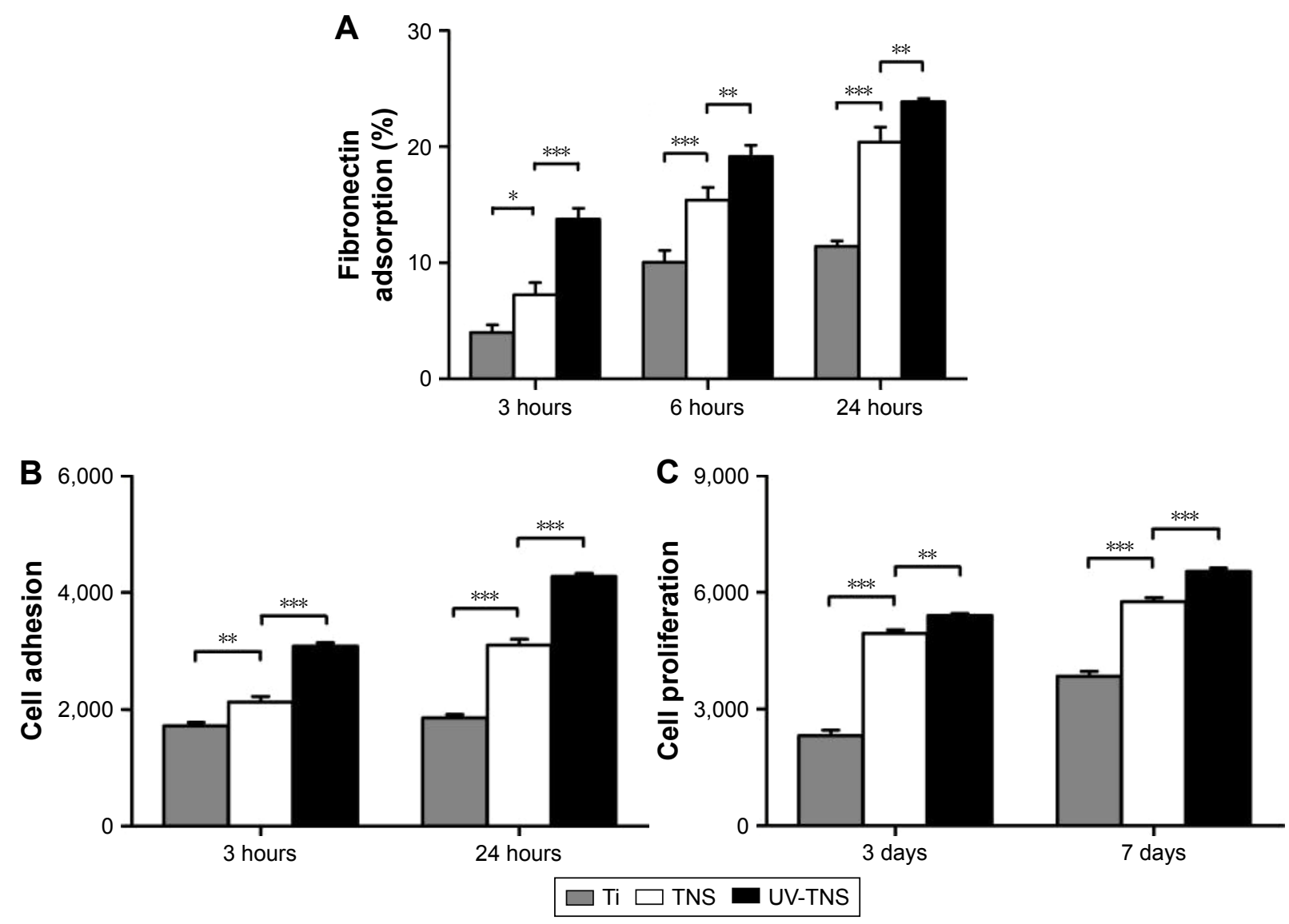

Figure 6 Adsorption of human fibronectin, cell adhesion, and proliferation of rBMMSCs on sample discs.

Notes: (A) Ti, TNS, and UV-TNS discs were incubated with human fibronectin solution $(500 \mu \mathrm{g} / \mathrm{mL})$ for 3,6 , and 24 hours at $37^{\circ} \mathrm{C}$ and quantified using the bicinchoninic acid method (***P<0.00I; $* * P<0.01$; $* P<0.05$ ). (B and $\mathbf{C}$ ) Ti, TNS, and UV-TNS discs were incubated with rBMMSCs and the levels of cell adhesion and proliferation were evaluated after 3 and 24 hours and 3 and 7 days, respectively, using a CellTiter-Blue ${ }^{\circledR}$ Cell Viability Assay (Promega Corporation, Madison, WI, USA) $(* * * P<0.00 I$; $* * P<0.01$ ).

Abbreviations: ALP, alkaline phosphatase; rBMMSCs, rat bone marrow mesenchymal stem cells; TNS, titanium with nanonetwork structures; UV-TNS, ultraviolet-treated titanium with nanonetwork structures.
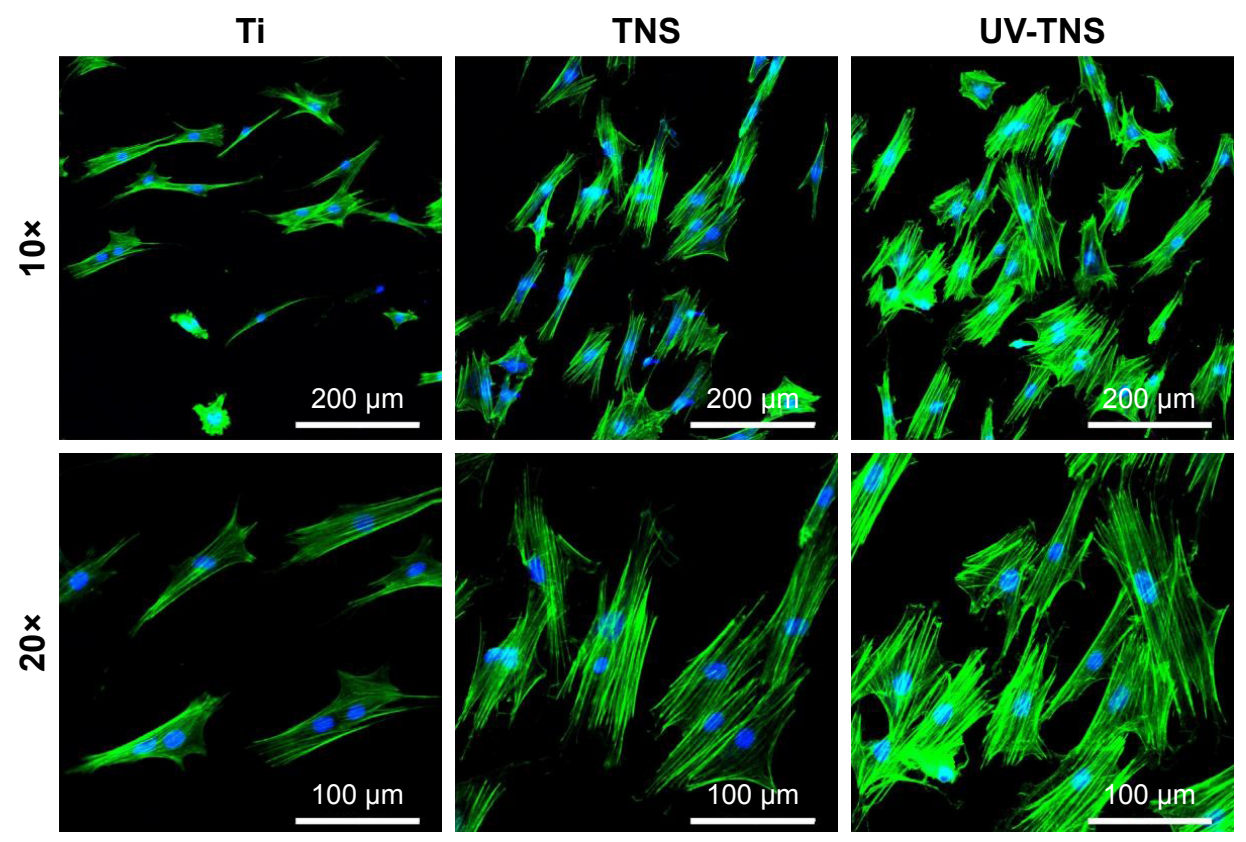

Figure 7 Morphological analysis of rBMMSCs attached to sample discs. Ti, TNS, and UV-TNS discs were incubated with rBMMSCs for 24 hours, stained with phalloidin (F-actin) and DAPI (nuclei), and visualized by fluorescence microscopy.

Abbreviations: rBMMSCs, rat bone marrow mesenchymal stem cells; TNS, titanium with nanonetwork structures; UV-TNS, ultraviolet-treated titanium with nanonetwork structures; DAPI, 4',6-diamidino-2-phenylindole. 

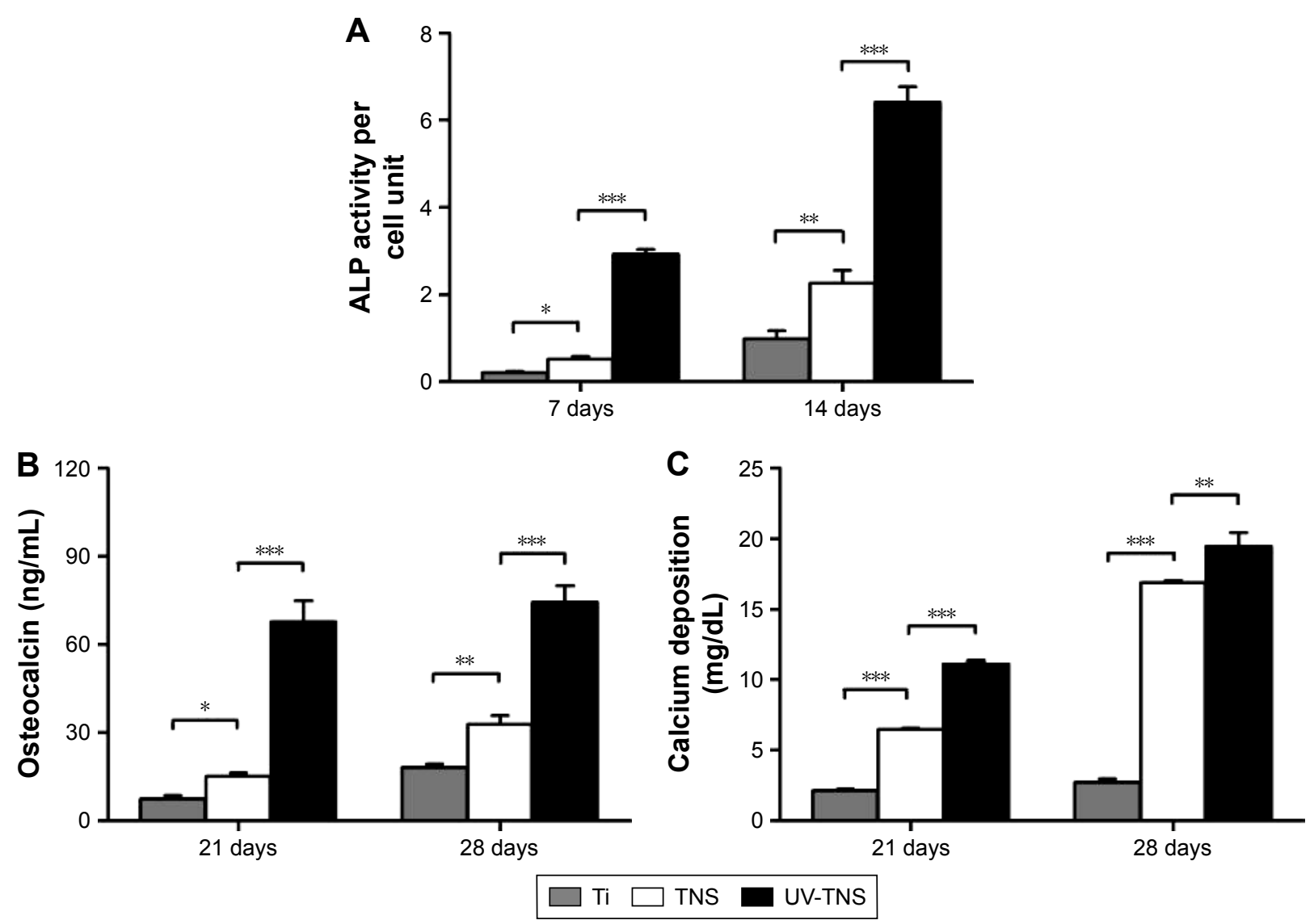

Figure 8 ALP activity, osteocalcin production, and calcium deposition in cells grown on sample discs.

Notes: rBMMSCs were cultivated on Ti, TNS, and UV-TNS discs for up to 28 days, and the levels of (A) ALP activity (7 and I4 days), (B) osteocalcin production ( 2 I and 28 days), and (C) calcium deposition ( $2 \mathrm{I}$ and 28 days) were evaluated as described in the "Materials and methods" section (***P<0.00I; $* * P<0.0 \mathrm{I} ; * P<0.05$ ).

Abbreviations: ALP, alkaline phosphatase; rBMMSCs, rat bone marrow mesenchymal stem cells; TNS, titanium with nanonetwork structures; UV-TNS, ultraviolet-treated titanium with nanonetwork structures.

observed on TNS as compared to Ti, UV-TNS effectively inhibited attachment and biofilm formation of $A$. oris. Moreover, the in vitro osteogenic activity of UV-TNS was significantly superior to that of TNS. These findings verified our hypothesis that UV treatment could enhance both the biological compatibility and the antimicrobial activity of TNS.

A. oris is an initial colonizer that can rapidly attach to both teeth and material surfaces and has been shown to co-aggregate with other oral bacterial pathogens, adhere to red blood cells, and develop biofilms. ${ }^{21,22}$ To investigate the effect of UV treatment on initial bacterial attachment to TNS, we chose to incubate sample discs with $A$. oris for a short duration (1 hour). The experimental results demonstrated that while the TNS surface is conducive to bacterial attachment, attachment was markedly inhibited by UV treatment. The most probable reason for postoperative infection of dental implants is contamination during implant insertion. As such, UV treatment to enhance TNS resistance to bacterial colonization within the oral environment during this period should lower the implant infection rates. Notably, none of the sample materials showed abundant numbers of dead bacteria or bacteria with abnormal morphologies, indicating that UV treatment did not convey bactericidal activity to TNS, but instead modified the surface of this material to prevent bacterial attachment. These findings were supported by the results of the SEM analysis. Antibacterial biomaterials are commonly modified with bactericidal adjunct substances, which also exert a certain degree of cytotoxicity toward the host. In contrast, UV treatment provides an optimal approach for preventing infections while avoiding long-term toxicity to the human body.

After surgery, the implant wound remains in direct contact with saliva and is therefore at risk of bacterial contamination until the recruitment of host immune cells, which typically occurs within 6 hours. During this period, bacteria can colonize the implant site and initiate the formation of biofilms, which are more resistant to host immunity than planktonic cells. ${ }^{17}$ In this study, UV treatment inhibited biofilm formation by $A$. oris, even after 6 hours of exposure to a high bacterial load $\left(>2 \times 10^{8} \mathrm{cfu} / \mathrm{mL}\right)$. Therefore, this 

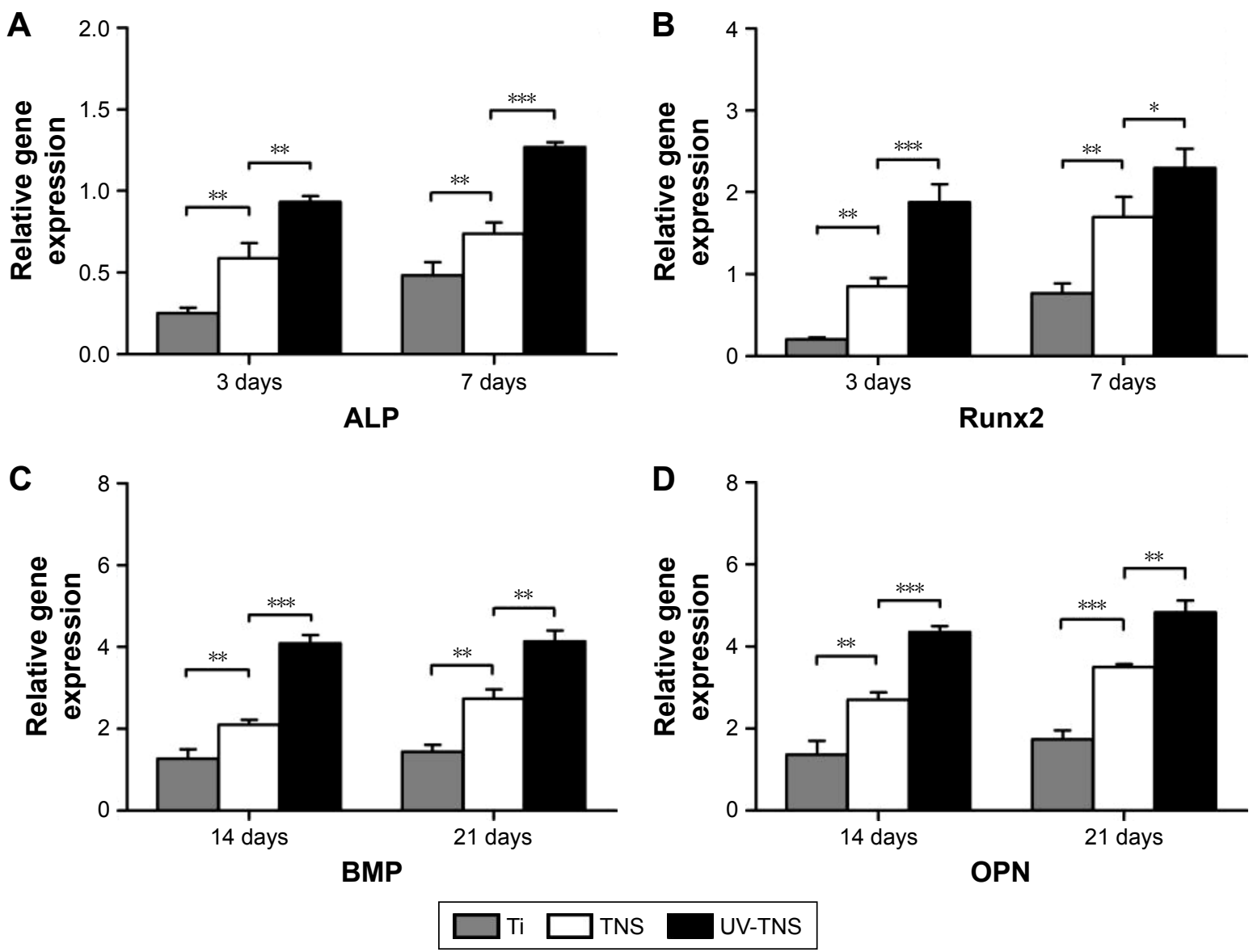

Figure 9 Expression of osteogenesis-related genes in cells grown on sample discs.

Notes: (A-D) The expression levels of the genes encoding ALP and Runx2 and OPN and BMP were evaluated in rBMMSCs cultivated on Ti, TNS, and UV-TNS discs at 3 and 7 days and 14 and 21 days, respectively, by real-time RT-PCR analysis ( $* * * P<0.00$ I; $* * P<0.01 ; * P<0.05)$.

Abbreviations: ALP, alkaline phosphatase; rBMMSCs, rat bone marrow mesenchymal stem cells; TNS, titanium with nanonetwork structures; UV-TNS, ultraviolet-treated titanium with nanonetwork structures; RT-PCR, reverse transcriptase polymerase chain reaction; BMP, bone morphogenetic protein; OPN, osteopontin.

treatment might be sufficient to protect the periimplant wound from bacterial contamination and chronic infection.

The higher rate of bacterial attachment observed on TNS than on Ti could be ascribed to differences in surface $\mathrm{pH}$. While newly prepared titanium surfaces are acidic, owing to the isoelectric point of $\mathrm{TiO}_{2}$ (between 5.6 and 6.1), the production of hydroxyl radicals on the TNS surface via the replacement reaction between $\mathrm{Na}^{+}$and $\mathrm{H}^{+}$renders this material basic, ${ }^{23,24}$ and basic surface conditions have been shown to promote the attachment of $A$. oris. ${ }^{25}$ A basic titanium surface was previously suggested to have a negative impact on bacterial attachment; ${ }^{26}$ however, the results of the present study clearly show that such surfaces yield enhanced colonization of $A$. oris.

Notably, compared to TNS, UV-TNS exhibited significantly improved in vitro osteogenic activity. Specifically, UV-TNS showed stronger protein adsorption and cell adhesion than TNS. Moreover, cell proliferation, the initial phase of osteogenic differentiation in rBMMSCs, was accelerated on UV-TNS, and the cells grown on this material exhibited higher ALP activity per cell unit as well as higher osteocalcin production, extracellular mineralization, and osteogenesisrelated gene expression than those grown on TNS. Together, these results indicate a comprehensive enhancement of osteogenic activity, from the initial to the final stages, on UV-TNS. Although an inverse correlation exists between cell proliferation and cell differentiation on microrough titanium surfaces, ${ }^{27,28} \mathrm{TNS}$ did not seem to conform to this trend; after 7 days of culture, cell proliferation and ALP activity were simultaneously accelerated on TNS. However, the cells grown on UV-TNS showed even higher levels of cell proliferation and ALP activity than those grown on TNS. This biological superiority might promote osseointegration in vivo, in terms of both bone mass and bone quality.

Upon UV treatment, we observed an inverse relationship between bacterial attachment and rBMMSC adhesion on the 
TNS surface. Again, this selective effect is likely due to the surface charge induced by high-intensity UV treatment. It is widely acknowledged that UV treatment of titanium surfaces results in the excitement of electrons from the valence band to the conduction band, which is followed by the abundant production of electron-hole pairs. Although electron-hole pairs on $\mathrm{TiO}_{2}$ eventually recombine, this process is relatively slow ${ }^{15}$ and has been shown to induce the formation of potential gradients, which can generate surface electrical currents. Remarkably, these currents promote the detachment of bacteria from titanium surfaces. ${ }^{29,30}$ As such, UV treatment renders the TNS surface bacteria repellent. Meanwhile, this treatment also promoted the attachment of rBMMSCs. Cell adhesion is key to osseointegration because it is the first step of cellular interaction with the implant surface. It is acknowledged that bone cells cannot effectively attach to titanium surfaces in the absence of adsorbed protein, ${ }^{31}$ and protein adsorption appears to depend more on electrostatic interactions than on hydrophilicity or bridge aid of divalent cations. ${ }^{32,33}$ Previous opinion held that $\mathrm{Na}^{+}$ions block anion sites on the titanium surface for $\mathrm{Ca}^{2+}$ binding, rendering the surface protein and cell inert. ${ }^{34}$ However, we recently demonstrated that TNS promotes the adsorption of protein due to its nanoscale surface, despite the abundance of surface $\mathrm{Na}^{+}$. Based on these findings, we hypothesized that high-intensity UV treatment could induce the formation of abundant electron-hole pairs on TNS within a short period, thereby inducing a relatively electropositive state and enabling the direct adsorption of negatively charged proteins without the bridge aid of divalent cations. ${ }^{24}$ Therefore, enhanced protein adsorption on UV-TNS favored rBMMSC adhesion. Although the mechanisms underlying these effects need to be verified by other surface analysis methods, the above-mentioned mechanism provides evidence that electrostatic interactions between mammalian cells or bacteria and TNS can be selectively modulated via a short-duration high-intensity UV treatment.

UV-TNS exhibited higher levels of fibronectin adsorption than TNS during the early phase, and both materials retained this fibronectin adsorption effect for 24 hours, indicating that electrostatic interactions were more important than the nanoscale structure during this initial phase. Conversely, at later time points, the TNS surface became occupied by fibronectin, after which the nanoscale structure superseded electrostatic interactions as the primary reason for adsorption. Machined titanium surfaces and acid-etched titanium surfaces reach the protein adsorption plateau after 2 and 6 hours, respectively. Although UV treatment enhances initial protein adsorption, the adsorption plateau for these materials appears after
2 hours. ${ }^{10}$ Compared with these titanium surfaces, TNS possesses a continuous protein adsorption capacity, while UV-TNS exhibits increased initial protein adsorption without sacrificing this continuous adsorption effect. Recently, the continuous protein adsorption effect was shown to yield continuous blood coagulation on implant surfaces, which benefited bone cell adhesion. ${ }^{35}$ This enhanced adsorption effect might therefore contribute to better osseointegration of UV-TNS.

While alkali-treated TNS is still at the in vitro research stage, the excellent osteogenic activity of this material has been confirmed. ${ }^{7}$ However, successful osseointegration depends not only on high-quality interaction between bone cells and implant materials, but also on minimizing bacterial contamination during early postoperational stages. At present, a UV light machine for dental chair-side treatment has been put into practical application, demonstrating convenience and good clinical outcomes. ${ }^{36-38}$ Given the results of the current study, we anticipate an even higher success rate for alkalitreated TNS induced by UV treatment technology.

\section{Conclusion}

In the present study, alkali-treated TNS was subjected to short-duration high-intensity UV treatment. Compared to TNS, UV-TNS exhibited superhydrophilicity and elimination of surface hydrocarbon contamination as well as lower initial bacterial attachment and biofilm formation. In addition, UV treatment enhanced adhesion, proliferation, and differentiation of rBMMSCs and promoted the expression of osteogenesis-related genes by the cells. This inverse relationship between bacterial attachment and mammalian cell adhesion was explained by the involvement of electron-hole pairs induced by UV treatment. We suggest that postoperative infections can be prevented and better osseointegration can be established on TNS by UV treatment.

\section{Acknowledgments}

This work was supported by the Japan Society for the Promotion of Science (grant numbers: 16K20524, 15K11185) and the Oral Implant Research Grant of Osaka Dental University (grant numbers: 16-01, 16-02). We are grateful to the members of the Department of Removable Prosthodontics and Occlusion, Department of Periodontology, for their kind advice and help. We thank Professor Pao-li Wang, Department of Bacteriology, Osaka Dental University, for his valuable discussions. We also thank Mr H Hori from the Central Institute of Dental Research, Osaka Dental University, for his kind help with the experimental techniques. 


\section{Disclosure}

The authors report no conflicts of interest in this work.

\section{References}

1. Xuereb M, Camilleri J, Attard NJ. Systematic review of current dental implant coating materials and novel coating techniques. Int $J$ Prosthodont. 2015;28:51-59.

2. Buser D, Janner SF, Wittneben JG, Bragger U, Ramseier CA, Salvi GE. 10-year survival and success rates of 511 titanium implants with a sandblasted and acid-etched surface: a retrospective study in 303 partially edentulous patients. Clin Implant Dent Relat Res. 2012;14:839-851.

3. Camps-Font O, Figueiredo R, Valmaseda-Castellon E, Gay-Escoda C. Postoperative infections after dental implant placement: prevalence, clinical features, and treatment. Implant Dent. 2015;24:713-719.

4. Paster BJ, Boches SK, Galvin JL, et al. Bacterial diversity in human subgingival plaque. J Bacteriol. 2001;183:3770-3783.

5. Ata-Ali J, Ata-Ali F, Ata-Ali F. Do antibiotics decrease implant failure and postoperative infections? A systematic review and meta-analysis. Int J Oral Maxillofac Surg. 2014;43:68-74.

6. Komasa S, Taguchi Y, Nishida H, Tanaka M, Kawazoe T. Bioactivity of nanostructure on titanium surface modified by chemical processing at room temperature. J Prosthodont Res. 2012;56:170-177.

7. Xing H, Komasa S, Taguchi Y, Sekino T, Okazaki J. Osteogenic activity of titanium surfaces with nanonetwork structures. Int J Nanomedicine. 2014;9:1741-1755.

8. Hu X, Neoh KG, Zhang J, Kang ET. Bacterial and osteoblast behavior on titanium, cobalt-chromium alloy and stainless steel treated with alkali and heat: a comparative study for potential orthopedic applications. J Colloid Interface Sci. 2014;417:410-419.

9. Jin $\mathrm{G}$, Qin $\mathrm{H}$, Cao H, et al. Synergistic effects of dual $\mathrm{Zn} / \mathrm{Ag}$ ion implantation in osteogenic activity and antibacterial ability of titanium. Biomaterials. 2014;35:7699-7713.

10. Aita H, Hori N, Takeuchi M, et al. The effect of ultraviolet functionalization of titanium on integration with bone. Biomaterials. 2009;30: 1015-1025.

11. Suzuki T, Hori N, Att W, et al. Ultraviolet treatment overcomes timerelated degrading bioactivity of titanium. Tissue Eng Part A. 2009;15: 3679-3688.

12. Aita H, Att W, Ueno T, et al. Ultraviolet light-mediated photofunctionalization of titanium to promote human mesenchymal stem cell migration, attachment, proliferation and differentiation. Acta Biomater. 2009;5:3247-3257.

13. Att W, Hori N, Iwasa F, Yamada M, Ueno T, Ogawa T. The effect of UV-photofunctionalization on the time-related bioactivity of titanium and chromium-cobalt alloys. Biomaterials. 2009;30:4268-4276.

14. Ueno T, Yamada S, Suzuki T, et al. Enhancement of bone-titanium integration profile with UV-photofunctionalized titanium in a gap healing model. Biomaterials. 2010;31:1546-1557.

15. Gallardo-Moreno AM, Pacha-Olivenza MA, Fernandez-Calderon MC, Perez-Giraldo C, Bruque JM, Gonzalez-Martin ML. Bactericidal behaviour of Ti6Al4V surfaces after exposure to UV-C light. Biomaterials. 2010;31:5159-5168.

16. Yamada Y, Yamada M, Ueda T, Sakurai K. Reduction of biofilm formation on titanium surface with ultraviolet-C pre-irradiation. J Biomater Appl. 2013;29:161-171.

17. de AvilaED, Lima BP, Sekiya T, et al. Effect of UV-photofunctionalization on oral bacterial attachment and biofilm formation to titanium implant material. Biomaterials. 2015;67:84-92.

18. Rosan B, Lamont RJ. Dental plaque formation. Microbes Infect. 2000;2: 1599-1607.

19. Vielkind P, Jentsch H, Eschrich K, Rodloff AC, Stingu CS. Prevalence of Actinomyces spp. in patients with chronic periodontitis. Int J Med Microbiol. 2015;305:682-688.
20. Zhao L, Liu L, Wu Z, Zhang Y, Chu PK. Effects of micropitted/ nanotubular titania topographies on bone mesenchymal stem cell osteogenic differentiation. Biomaterials. 2012;33:2629-2641.

21. Periasamy S, Kolenbrander PE. Mutualistic biofilm communities develop with Porphyromonas gingivalis and initial, early, and late colonizers of enamel. J Bacteriol. 2009;191:6804-6811.

22. Mishra A, Wu C, Yang J, Cisar JO, Das A, Ton-That H. The Actinomyces oris type 2 fimbrial shaft FimA mediates co-aggregation with oral streptococci, adherence to red blood cells and biofilm development. Mol Microbiol. 2010;77:841-854.

23. Kim HM, Miyaji F, Kokubo T, Nakamura T. Preparation of bioactive Ti and its alloys via simple chemical surface treatment. J Biomed Mater Res. 1996;32:409-417.

24. Att W, Hori N, Takeuchi M, et al. Time-dependent degradation of titanium osteoconductivity: an implication of biological aging of implant materials. Biomaterials. 2009;30:5352-5363.

25. Caous JS, Lovenklev M, Faldt J, Langton M. Adhesion of Streptococcus mitis and Actinomyces oris in co-culture to machined and anodized titanium surfaces as affected by atmosphere and pH. BMC Oral Health. 2013;13:4.

26. Li J, Wang G, Wang D, Wu Q, Jiang X, Liu X. Alkali-treated titanium selectively regulating biological behaviors of bacteria, cancer cells and mesenchymal stem cells. J Colloid Interface Sci. 2014;436:160-170.

27. Malaval L, Liu F, Roche P, Aubin JE. Kinetics of osteoprogenitor proliferation and osteoblast differentiation in vitro. J Cell Biochem. 1999;74:616-627.

28. Stein GS, Lian JB, Owen TA. Relationship of cell growth to the regulation of tissue-specific gene expression during osteoblast differentiation. FASEB J. 1990;4:3111-3123.

29. van der Borden AJ, van der Werf H, van der Mei HC, Busscher HJ. Electric current-induced detachment of Staphylococcus epidermidis biofilms from surgical stainless steel. Appl Environ Microbiol. 2004; 70:6871-6874.

30. van der Borden AJ, van der Mei HC, Busscher HJ. Electric block current induced detachment from surgical stainless steel and decreased viability of Staphylococcus epidermidis. Biomaterials. 2005;26:6731-6735.

31. Zhang H, Bremmell K, Kumar S, Smart RS. Vitronectin adsorption on surfaces visualized by tapping mode atomic force microscopy. J Biomed Mater Res A. 2004;68:479-488.

32. Iwasa F, Hori N, Ueno T, Minamikawa H, Yamada M, Ogawa T. Enhancement of osteoblast adhesion to UV-photofunctionalized titanium via an electrostatic mechanism. Biomaterials. 2010;31:2717-2727.

33. Hori N, Ueno T, Minamikawa H, et al. Electrostatic control of protein adsorption on UV-photofunctionalized titanium. Acta Biomater. 2010; 6:4175-4180.

34. Klinger A, Steinberg D, Kohavi D, Sela MN. Mechanism of adsorption of human albumin to titanium in vitro. J Biomed Mater Res. 1997; 36:387-392.

35. Kopf BS, Ruch S, Berner S, Spencer ND, Maniura-Weber K. The role of nanostructures and hydrophilicity in osseointegration: In-vitro protein-adsorption and blood-interaction studies. J Biomed Mater Res. 2015;103(8):2661-2672.

36. Kitajima H, Ogawa T. The use of photofunctionalized implants for low or extremely low primary stability cases. Int J Oral Maxillofac Implants. 2016;31:439-447.

37. Funato A, Ogawa T. Photofunctionalized dental implants: a case series in compromised bone. Int J Oral Maxillofac Implants. 2013;28: 1589-1601.

38. Suzuki S, Kobayashi H, Ogawa T. Implant stability change and osseointegration speed of immediately loaded photofunctionalized implants. Implant Dent. 2013;22:481-490. 


\section{Publish your work in this journal}

The International Journal of Nanomedicine is an international, peerreviewed journal focusing on the application of nanotechnology in diagnostics, therapeutics, and drug delivery systems throughout the biomedical field. This journal is indexed on PubMed Central, MedLine, CAS, SciSearch $\AA$, Current Contents $\AA /$ Clinical Medicine,

Journal Citation Reports/Science Edition, EMBase, Scopus and the Elsevier Bibliographic databases. The manuscript management system is completely online and includes a very quick and fair peer-review system, which is all easy to use. Visit http://www.dovepress.com/ testimonials.php to read real quotes from published authors.

Submit your manuscript here: http://www.dovepress.com/international-journal-of-nanomedicine-journal 